\title{
EDUCAÇÃO: UM NOVO \\ PATAMAR INSTITUCIONAL
}

Maria Aparecida Azevedo Abreu

\section{RESUMO}

O objetivo deste artigo é realizar uma avaliação da política de educação do Governo Lula em seus dois mandatos (2003-2010). Para isso, em primeiro lugar, é feito um breve diagnóstico do contexto educacional do país em 2002. Em seguida, analisa-se o primeiro (2003-2006) e o segundo (20072010) mandatos do presidente, quando o foco passa a ser o Plano de Desenvolvimento da Educação (PDE).

PALAVRAS-Chave: Política educacional; educação básica e superior; Plano de Desenvolvimento da Educação.

\section{ABSTRACT}

The article offers an overview of educational policies in Lula's both terms as president (2003-2010). A brief diagnosis of the educational system in 2002 is proposed, followed by analysis of the first (2003-2006) and second (2007-2010) terms, when the National Plan for Education is established.

KEYWORDS: Educational policies; basic schooling; advanced schooling; National Plan for Education.

\section{O CONTEXTO DA EDUCAÇÃO EM 2002}

[1] LDB, Lei no 9.394, de 20 dez. 1996.

[2] Emenda Constitucional $n^{\circ}$ 14, de 12 set. 1996, regulamentada pela Lei ${ }^{\circ}$ 9.424, de 24 dez. 1996.
A área de educação foi marcada na década de 1990 pela aprovação da Lei de Diretrizes e Bases da Educação' ${ }^{1}$. Nesta lei, os níveis de educação foram divididos em educação básica e superior; a educação básica, por sua vez, foi dividida em ensino infantil, fundamental e médio. Educação profissional e educação especial foram estabelecidas como modalidades específicas, mas integradas aos diversos níveis de ensino. Em tal contexto legal, e de acordo com os principais problemas educacionais do país, a política educacional daquela década foi marcada pela expansão do ensino fundamental e do ensino superior privado. A principal demanda era a de universalizar o ensino obrigatório (então de oito anos) e possibilitar maior acesso à educação superior. As medidas principais foram a criação do Fundo de Desenvolvimento e Manutenção do Ensino Fundamental (Fundef)2 e o estímulo à abertura de novos cursos superiores pela rede privada. 
Tais medidas contribuíram, de fato, para a universalização do ensino fundamental e para o aumento do número de alunos no ensino superior, mas ao mesmo tempo contribuíram para a persistência da baixa qualidade da educação básica e para o surgimento de uma educação superior privada também de baixa qualidade³.

Esse quadro foi constatado pelos sistemas de avaliação criados pelo próprio governo, o Sistema de Avaliação da Educação Básica (Saeb) e o Exame Nacional de Cursos Superiores, que ficou conhecido como Provão. Na educação básica, percebia-se que, embora o ensino fundamental tivesse sido universalizado, isso não havia garantido a progressão desses alunos ao ensino médio e à educação superior. Constatavam-se, ainda, insuficiências na educação infantil, com conseqüências para a aprendizagem dos alunos no ensino fundamental. Na educação superior, o número de vagas ociosas indicava que a política de expansão chegava ao seu limite. Além disso, desigualdades regionais eram evidentes, e os estados do Norte e do Nordeste apresentavam índices educacionais inferiores aos do Sul e Sudeste4. Assim, ao final dos dois mandatos do governo Fernando Henrique Cardoso, embora tenha havido uma política exitosa de expansão da educação, as demandas relativas à educação básica estabelecidas no Plano Nacional de Educação (PNE), aprovado por meio de Lei em $2001^{5}$, se voltavam para uma maior atenção ao ensino infantil e ao ensino médio, e, na educação superior, para uma expansão da rede pública e para a melhoria da qualidade da educação privada, com atenção para as disparidades regionais.

Com essas demandas, a pressão incidia sobre o aumento de recursos na educação básica como um todo, sendo o ensino médio visto como o nó górdio que impedia o acesso dos estudantes à educação superior ${ }^{6}$. Era preciso, então, expandir também o ensino médio e melhorar sua qualidade, para que estudantes de escolas públicas de educação básica tivessem acesso à educação superior de boa qualidade. Ao lado disso, foi se formando um consenso de que a melhoria da qualidade passava por uma valorização do professor, carreira caracterizada pelos baixos salários e, por causa disso, destituída de estímulos para o aprimoramento dos professores em atividade, pouco atraente para novos quadros. Áreas como biologia, química e física careciam de professores, pois os alunos dos cursos de graduação dessas disciplinas não tinham estímulo para cursarem licenciaturas, voltando-se para o bacharelado e carreiras mais atraentes. Era necessário, portanto, reverter esse processo com o intuito de que os resultados do processo de expansão fossem mantidos e, ainda, houvesse uma melhoria na qualidade da educação já expandida.

Embora esses problemas fossem de constatação geral, a educação era vista ainda, nas ações implementadas pelos governos, em seus di-
[3] "Políticas sociais: acompanhamento e análise $n^{\circ} 5^{\prime \prime}$. Brasília: Ipea, ago. 2002.

[4] Ibidem.

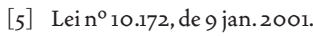

[6] Conforme o diagnóstico integrante do PNE. Ver também Rigotto, M. E. e Souza, N. de J. "Evolução da educação no Brasil: 1970-2003". Análise, 2005, vol.16, n 2, pp.339-58. 
[7] Revogação do Decreto ${ }^{\circ} 2.208$, de 17 abr. 1997, por meio do Decreto $n^{\circ} 5.154$, de 23 jul. 2004, atendendo a diversas demandas (Frigoto, G. Ciavatta, M. e Ramos, M. “A política de educação profissional no Governo Lula:um percurso histórico controvertido". Educação e Sociedade, 2005, vol. $26, n^{\circ} 92$, pp. $1087-113$, p. 1089 ).

[8] Lei n ${ }^{\circ} 11.096$, de 13 jan. 2005. ferentes níveis, de forma pouco integrada, como se os problemas na educação básica não dissessem respeito à educação superior. A educação básica pública era de baixa qualidade, e a educação superior pública era considerada de alta qualidade, mas pouco podia contribuir com a melhoria da primeira.

\section{O GOVERNO LULA: PRIMEIRO MANDATO (2003-2006)}

No primeiro mandato do presidente Lula, três ministros ocuparam a pasta da Educação. Cristóvão Buarque iniciou seu mandato junto com o presidente e deixou o cargo em 27 de janeiro de 2004, tendo sido sucedido por Tarso Genro, que foi titular da pasta até 29 de julho de 2005, quando assumiu a presidência do Partido dos Trabalhadores, epassou a ser ministro o então Secretário Executivo do Ministério, Fernando Haddad. Este primeiro período foi marcado por certa instabilidade que marcava todo o mandato do presidente, em decorrência das denúncias de corrupção envolvendo diversos setores do governo e que teve seus efeitos sobre a estabilidade na titularidade da pasta. Essa instabilidade, no entanto, não impediu que fossem enviados para o Congresso importantes textos legais, como os que deram origem ao Fundo de Desenvolvimento e Manutenção da Educação Básica e de Valorização dos Profissionais da Educação (Fundeb), nem que se instaurasse uma nova concepção do papel da educação profissional7. Logo no início do governo, em 2003, foi estruturado também o programa Brasil Alfabetizado, que cuida da alfabetização de jovens e adultos, priorizando as regiões Norte e Nordeste do país. Além disso, na gestão de Tarso Genro, foi instituído o programa Universidade para Todos (ProUni) ${ }^{8}$, que obriga as universidades privadas a destinar bolsas de estudo integrais ou parciais como contrapartida à isenção fiscal da qual elas são beneficiadas.

Embora a aprovação da Lei que institui o ProUni tenha sido comemorada por muitos, este programa foi objeto de severas críticas, tanto dos setores ligados às instituições privadas de ensino superior como dos defensores da universidade pública. Estes defendiam que a prioridade do governo fosse a ampliação e a qualificação da rede pública de educação superior, e aqueles criticavam a excessiva ingerência do Estado. Esta crítica já vinha se fundamentando na aprovação da Lei $\mathrm{n}^{\circ}$ 10.861, de 14 de abril de 2004, que instituiu o Sistema Nacional de Avaliação da Educação Superior (Sinaes) e que se reforçou com a publicação do Decreto $n^{\circ} 5.773$, de 9 de maio de 2006 , criando um novo marco regulatório para a educação superior no país. O Sinaes constituiu um ciclo de avaliação de três anos, em que alunos, cursos e instituições passaram a ser avaliados e, a partir disso, objeto de ações de regulação pela União. Os alunos passaram a ser examinados pelo 
Exame Nacional de Avaliação do Desempenho Estudantil (Enade), e os cursos e instituições, por avaliações in loco, para que fossem autorizados, reconhecidos, credenciados ou recredenciados. Com isso, a educação superior passou a ser avaliada pelo desempenho dos estudantes, pelo projeto pedagógico dos cursos e pela qualidade docentee de infra-estrutura das instituições.

Assim, no primeiro mandato foi construída a base para a atuação do ministério em todos os níveis de ensino e também na modalidade profissional 9 . A educação básica teria uma nova sistemática de distribuição de recursos, tendo como referência não somente o ensino fundamental, como se dava anteriormente com o Fundo de Manutenção e Desenvolvimento do Ensino Fundamental ${ }^{10}$, mas também o ensino infantil e o médio. O ensino infantil foi incluído na destinação dos recursos do Fundeb como conseqüência da forte atuação da Campanha Nacional pelo Direito à Educação. Por sua vez, a educação superior recebia um novo marco regulatório para que a expansão da rede privada de ensino superior ocorrida no governo anterior tivesse sua qualidade verificada por processos de avaliação periódicos e referenciados pelo Ministério da Educação. O ensino tecnológico voltou a ter seu estatuto de formação destinada à vida profissional, tanto na educação de nível médio como de nível superior, de forma integrada e não sob a influência das demandas estritamente empresariais, como reivindicavam os setores ligados a essa modalidade de educação.

\section{EDUCAÇÃO NO SEGUNDO MANDATO DO GOVERNO LULA (2007-2010)}

O lançamento do Plano de Desenvolvimento da Educação (PDE), em abril de 2007, marcou o início do segundo mandato do governo Lula no campo da educação. O Plano, documento de organização do poder Executivo, estava estruturado inicialmente em trinta ações de portes variados e voltadas para todos os níveis e modalidades da educação. Um exame detalhado dessas ações não seria a estratégia mais interessante nem a mais adequada para a abordagem desse Plano, que norteou toda a ação do Ministério da Educação nesses últimos quatro anos. Por isso, sua análise aqui será estruturada em três partes: i) a concepção de política educacional que o permeou; ii) o alcance institucional de suas ações; iii) os resultados numéricos obtidos a partir de sua aplicação.

\section{Uma tradução institucional de uma visão sistêmica da educação}

Quando lançado, o Plano de Desenvolvimento da Educação foi muito bem recebido, por sinalizar a priorização da educação no segundo mandato do governo Lula, já indicando um conjunto de ações a serem implementadas, mas também despertou algumas críticas ${ }^{11}$ :
[9] De acordo com os níveis e as modalidades de educação estabelecidos na Lei de Diretrizes e Bases (LDB).

[10] Instituído pela Emenda Constitucional $\mathrm{n}^{\circ} 14$, de 12 set. 1996 , e regulamentado pela Lei $n^{\circ} 9.424$, de 24 dez. 1996.
[11] Saviani, D., "O Plano de Desenvolvimento da Educação: Análise do Projeto do MEC". Educação e Sociedade, 2007, vol.28, n 100, pp.1231-1255. 
[12] Decreto no 6.094, de 24 abr. 2007.

[13] Haddad, S., Carvalho, L. e Saraiva, S. Uma avaliação da participação da sociedade civil e da colaboração interministerial do Plano de Desenvolvimento da Educação (PDE). Estudo de Caso Brasil 2008. São Paulo: Ação Educativa, 2008, p. 16.

[14] Emil dez.2009.

[15] É importante notar ainda que o PDE foi lançado num contexto em que o ministro Fernando Haddad tinha sua permanência no cargo em discussão na reforma ministerial ocorrida na época. Diante disso, seria difícil imaginar que o Plano fosse lançado com a ampla participação da sociedade civil (Haddad, Carvalho e Saraiva, op. cit., p.16).

[16] A Desvinculação das Receitas da União estabelecida no artigo 76 do Ato das Disposições Constituições Transitórias abria uma exceção na vinculação constitucional relativa aos recursos da União para a educação. Com o seu fim, em 2010 os recursos da educação aumentaram em R $\$ 7$ bilhões, sendo que, a partir de 2001,0 aumento tinha sido estimado em $\mathrm{R} \$$ 10 bilhões por ano. i) a insuficiência das ações, dada a improbabilidade de aumento dos recursos para a área, a partir da política econômica adotada pelo governo federal e ii) a ausência de participação da sociedade na proposição das ações contidas no Plano.

As críticas, bastante fundamentadas e legítimas, fez com que o $\mathrm{PDE}$ fosse recebido com certo ceticismo por alguns setores ligados à educação no país, bastante conhecedores da profundidade e da extensão dos problemas nacionais nessa área. No entanto, o que pôde ser verificado é que o ceticismo foi perdendo sua razão de ser, à medida que o Plano foi sendo implementado. Vejamos.

O segundo ponto de crítica baseou-se no fato de que o decreto "Compromisso Todos pela Educação" 12 , publicado junto com o lançamento do Plano, era o mesmo nome de uma organização da sociedade civil conduzida em sua maioria por empresários e fundações empresariais ${ }^{13}$. No entanto, embora efetivamente pareça não ter havido a consulta direta a setores da área de educação, suas ações são resultado das demandas e das necessidades que já vinham sendo apontadas em diversos fóruns e pelo próprio debate público da área. Além disso, as principais ações do Plano constituíram-se por meio de leis votadas no congresso e, portanto, resultaram de processos que envolveram os legítimos representantes da sociedade brasileira que reconheceram - como no caso do Fundeb, em que o ensino infantil foi incluído na destinação dos recursos do Fundo - as demandas da população. A concepção de política educacional que sustenta o PDE, voltada para o acesso e a permanência do aluno na escola, acabou por ser sacramentada na Emenda Constitucional $n^{\circ} 59^{14}$, que, num amplo envolvimento parlamentar e social, determinou que os sistemas de ensino estabelecessem regimes de colaboração, que o atendimento do educando envolvesse programas de acesso e permanência do aluno na escola e o estabelecimento de metas de aplicação de recursos públicos em educação como proporção do produto interno bruto.Assim, embora o anúncio do PDE não tenha sido precedido de audiências públicas ${ }^{15}$ ou de reuniões amplas com a população, ele não foi contrário ao que a área deeducação efetivamente demandava, como posteriormente reconhecido por ampla maioria do Congresso Nacional.

Já em relação à primeira crítica, referente ao montante de recursos destinados à área, o fim da Desvinculação das Receitas da União (DRU) ${ }^{16}$ em relação aos recursos da educação certamente mudou esse quadro, importando num aumento substancial de recursos já para o exercício de 2010, conforme a Emenda Constitucional n 59 . Além disso, em tal Emenda está previsto que a mesma lei que estabelecer o novo PNE deverá estabelecer metas de aplicação dos recursos em proporção definida em relação ao PIB. Portanto, mais um ponto decisivo a atenuar o ceticismo inicial. 
Reconhecidas e relativizadas as críticas iniciais ao PDE, resta verificar a concepção de política educacional que o sustenta. Em primeiro lugar, o programa concebe a educação tendo como foco a autonomia do indivíduo, como já apontado. Em segundo, pretende promover o "enlace entre educação e ordenação territorial", o que está relacionado com o papel que a União, com este Plano, avocou pra si, de se constituir em um agente democratizador, responsável pelo desenvolvimento regional, minimizando desigualdades regionais que produzam iniqüidade de oportunidades e de acesso a serviços públicos de qualidade. Com isso, o Ministério da Educação transformou-se no principal agente promotor da igualdade na educação nacional e houve uma federalização da responsabilidade pela educação. Por fim, na expressão que esteve presente em boa parte dos documentos oficiais sobre educação desde o lançamento do Plano, a defesa de uma "visão sistêmica da educação", que consiste numa visão articulada entre os diversos níveis e modalidades de ensino. Com essa visão, educação básica e educação superior deixaram de ser fragmentos estanques e foram integradas, e a educação profissional deixou de ser apenas uma modalidade residual, passando a ter papel decisivo na formação de quadros para o mundo do trabalho ea oferecer alternativas para jovens e adultos que queiram uma formação voltada para a área de tecnologia. Essa valorização da educação profissional e tecnológica, que teve como pontapé inicial a revogação do Decreto $n^{0} 2.208^{17}$, anteriormente mencionado, deixa pra trás um arraigado preconceito existente contra essa modalidade de educação como sendo "inferior" à educação tradicional ${ }^{18}$ (Bourdieu, 2006) e foi reforçada não só pela própria expansão da oferta da rede pública, como também pela equiparação salarial de seus professores com os professores das universidades federais.

Embora isto ainda não tenha sido detalhado do ponto de vista institucional, pode-se dizer que a concepção de política educacional que sustenta o PDE antecipa a "nacionalização da educação", reivindicada por Saviani ${ }^{19}$.

\section{Oalcance institucional das ações do PDE}

Afirmar que o PDE é uma "tradução institucional de uma visão sistêmica de educação" não é suficiente para explicitar seu alcance institucional. Uma das marcas das ações contidas no Plano é justamente a preocupação em tornar suas medidas o mais institucionalizadas possível e, portanto, sua continuação para além dessa gestão. Isto não quer dizer redução da discricionariedade política do próximo titular da pasta ou do próximo governante do país, mas sim a construção de um aparato institucional que pode servir para as próximas gestões darem passos adiante e realizarem ainda mais
[17] Em 17 abr. 2007.

[18] Bourdieu, Pierre. Escritos sobre Educação. Organizado por Maria Alice Nogueira e Afrânio Catani. Petrópolis: Vozes, 2006.

[19] Saviani, op. cit. 
[20] Decreto $\mathrm{n}^{\circ} 6.094$, de 24 abr. 2007.

\begin{abstract}
[21] Isto é o que está explicitamente indicado no art. $1^{\circ}$ do Decreto $\mathrm{n}^{\circ}$ 6.094, de 24 abr. 2007: "O Plano de Metas Compromisso Todos pela Educação (Compromisso) é a conjugação dos esforços da União, Estados, Distrito Federal e Municípios, atuando em regime de colaboração, das famílias e da comunidade, em proveito da melhoria da qualidade da educação básica".
\end{abstract}

[22] O Sistema foi premiado pela Escola Nacional de Administração Pública - Enap, no $13^{\circ}$ Concurso Inovação na Gestão Pública, em 2009.

[23] "Sistemas de ensino" é uma terminologia utilizada pela LDB, utilizada no seguinte contexto: "Art. $8^{\circ}$ a União, os Estados, o Distrito Federal e os Municípios organizarão, em regime de colaboração, os respectivos sistemas de ensino".

[24] Fernandes, R. e Gremaud, A. Avaliação da qualidade na educação no Brasil. Brasília: Inep/Fundação Santiliana, 2008, p. 6. ações que possibilitem os avanços de que a educação necessita. Consideremos essas medidas, segundo os diferentes níveis de ensino.

\section{Educação básica}

Na educação básica, as ações do PDE foram estruturadas a partir do decreto conhecido como "Compromisso Todos pela Educação" 20 . Nele foram instituídas ações que deveriam ser acordadas entre a União e os demais entes da federação por meio de convênios e definidas em Planos de Ações Articuladas. Trata-se, portanto, de um regime de colaboração ${ }^{21}$.Aassinatura e a execução desses convênios, que compreendiam um verdadeiro pacto nacional pela melhoria da educação, tornaram necessária a criação de uma estrutura institucional e de tecnologia da informação capaz de instrumentalizar o acompanhamento do cumprimento das obrigações firmadas. Neste contexto foi criado o Sistema Integrado de Planejamento, Orçamento e Finanças do Ministério da Educação $(\text { Simec })^{22}$.

Para a verificação do cumprimento das metas fixadas, foi criado o Índice de Desenvolvimento da Educação Básica (Ideb), indicador objetivo combinando o desempenho escolar dos alunos com o fluxo das aprovações. Essa combinação levava em consideração os mecanismos de avaliação já existentes, o censo educacional e os exames nacionais Prova Brasil e Exame Nacional do Ensino Médio (Enem). Os sistemas de ensino ${ }^{23}$, portanto, deveriam preocupar-se com a qualidade do aprendizado dos alunos e com seu progresso nas séries do ensino regular. A criação de um indicador nacional era necessária para que se construísse um sistema de accountability não somente da política federal de educação, mas de todos os entes federativos, tornando possível a todos os cidadãos acompanhar o desempenho da educação de sua cidade e até mesmo da escola em que seus filhos estão estudando. No caso do Brasil, o Ideb "foi, também, utilizado para estabelecer metas para redes e escolas e, assim, propiciar uma movimentação nacional para que, até 2021 , o Brasil atinja o estágio educacional atual dos países desenvolvidos" 24 . As metas para cada estado do país foram estabelecidas de acordo com o esforço que cada um teria que fazer para contribuir com a sua parte para a obtenção de um Ideb 6, que é uma comparação do Brasil com os países da Organização para a Cooperação e o Desenvolvimento Econômico (OCDE). O Ideb constituiu, dessa forma, um passo adiante ao Saeb, aproveitando as informações nele contidas.

Assim, o PAR e o Ideb foram os principais componentes do regime de colaboração organizado pelo MEC com o decreto "Compromisso Todos pela Educação". Esse regime de colaboração, se não foi suficiente para a constituição de um Sistema Nacional de Educação, tal como pretendido no Documento de Referência da Conferência Nacional de 
Educação, realizada em abril de 2010 , certamente constituiu uma experiência e um passo fundamentais para isso.

Junto com o regime de colaboração, o processo de nacionalização da educação teve como elemento também a aprovação ${ }^{25}$ de um piso salarial para os profissionais do magistério público da educação básica de $\mathrm{R} \$ 950,00$ reais. Embora se reconheça que este piso é insuficiente para a valorização do magistério, constituiu medida importante para o estabelecimento de um patamar nacional mínimo, garantindo condições igualitárias para os professores em todo território nacional.

Essas medidas, ancoradas na existência do Fundeb, podem ser consideradas estruturais rumo à constituição de um sistema nacional de educação, tal como preconizado na última conferência nacional de educação. Ao lado delas, várias outras foram tomadas, para que fossem possibilitados o acesso do aluno à escola e a sua permanência nela, como o programa de Merenda Escolar, Caminho da Escola e Proinfância.

\section{Educação superior}

No âmbito da rede pública de educação superior, a ação do governo federal foi estruturada em torno do Programa de Apoio a Planos de Reestruturação e Expansão das Universidades Federais (Reuni).A marca característica deste programa foi a exigência de que as universidades elaborassem planos de reestruturação que deveriam compreender, entre outras coisas, dobrar o número de alunos em dez anos (a partir de 2008 ) e implementar medidas democratizantes em sua estrutura. Todas as 55 universidades federais aderiram. O programa tornou o investimento em reestruturação atrativo para as universidades, o que em si apresenta uma vantagem institucional relevante. Além disso, outras novas universidades foram criadas. No âmbito da rede privada de ensino superior, além do ProUni, criado no primeiro mandato do presidente Lula, foram definidas regras mais favoráveis aos estudantes para o Fundo de Financiamento ao Estudante do Ensino Superior (Fies) ${ }^{26}$.

Além dessas medidas de viabilização do acesso dos estudantes ao ensino superior da rede privada, foram executadas e aprofundadas as medidas adotadas para a regulação da educação superior já iniciadas no mandato anterior. Para a regulação da educação superior, foram editados vários textos normativos e criado um novo sistema de tramitação de processos de regulação, o E-MEC, que permitiu uma maior agilidade dos processos administrativos, bem como sua tramitação integralmente na forma digital. Foram realizadas também várias ações de supervisão de cursos e instituições, resultando em medidas cautelares, redução de vagas e até mesmo encerramento de alguns cursos. A atividade de avaliação dos cursos foi racionalizada, tornando desnecessárias avaliações de instituições e cursos considerados de
[25] Lei n ${ }^{\circ} 11.378$, de 16 jul. 2008.

[26] Lei ${ }^{\circ} 12.202$, de 14 jan. 2010 , que alterou dispositivos da Lei $\mathrm{n}^{\circ}$ 10.260 , de 12 jul. 2001, que dispõe sobre o Fies. 
qualidade satisfatória, de acordo com os indicadores utilizados nos instrumentos de avaliação.

Além de todas essas medidas que dizem respeito à expansão e qualificação da educação superior, este nível de ensino teve sua responsabilidade sobre a formação de professores aumentada nesta última gestão do governo Lula. A Lei n ${ }^{0} 11.502$, de 11 de julho de 2007 , atribuiu à Coordenação de Aperfeiçoamento de Pessoal de Nível Superior (Capes) a finalidade de estabelecer colaboração com os estados e municípios para a formação inicial e continuada de profissionais do magistério. Esta atribuição reafirma a visão sistêmica da educação que fundamentou o PDE, ao integrar educação básica e educação superior, tornando esta responsável pelos quadros qualificados daquela, o que contribuiu, portanto, para a melhoria da qualidade da educação básica.

\section{Educação tecnológica}

A rede federal de educação profissional, científica e tecnológica foi objeto de uma vultosa expansão no segundo mandato do atual presidente. De forma complementar, as redes estaduais contaram com o Programa Brasil Profissionalizado, criado em 2007, que possibilita a modernização e a expansão das redes públicas de ensino médio integradas à educação profissional.

Além da expansão e modernização da rede existente, a maioria dos Centros Federais de Educação Tecnológica (Cefets) passou a ser Institutos Federais de Educação, Ciência e Tecnologia (Ifets), instituições de educação básica, superior e profissional, pluricurriculares e multicampi, especializadas na oferta de educação profissional e tecnológica nas diferentes modalidades de ensino (presencial e à distância), com base na conjugação de conhecimentos técnicos e tecnológicos ${ }^{27}$. No que tange à educação superior, os Ifets são dotados de autonomia semelhante às das universidades para a criação e a extinção de seus cursos.

Por fim, em 2008 foi realizado um acordo entre o governo federal e as entidades do denominado Sistema $S$, que reúne entidades como Serviço Social da Indústria (Sesi), Serviço Social do Comércio (Sesc), Serviço Nacional de Aprendizagem Industrial (Senai) e Serviço Nacional de Aprendizagem Comercial (Senac). Senai e Senac passaram a ter de aplicar dois terços de sua receita na oferta de cursos profissionalizantes gratuitos para jovens de baixa renda. Já o Sesi e o Sesc tiveram que investir um terço de sua receita em ações educativas. Trata-se de uma medida que ampliou a oferta de vagas gratuitas na educação tecnológica e, além disso, inseriu uma correção num sistema que é financiado com recursos públicos, oriundo do recolhimento de contribuições compulsórias das empresas, que anteriormente tinha um percentual muito baixo de destinação a vagas gratuitas. 
É preciso salientar que a expansão da educação profissional e tecnológica tem duas vertentes: uma voltada para a educação superior, que implica o aumento de vagas em cursos necessários para o desenvolvimento do país; outra voltada para o ensino médio, constituindo mais um estímulo para que os jovens prossigam seus estudos.

\section{Números e recursos}

O orçamento do Ministério da Educação passou de cerca de $\mathrm{R} \$ 18$ bilhões em 2002 para cerca de $\mathrm{R} \$ 49$ bilhões em $2010^{28}$. Esse aumento de orçamento foi reflexo da decisão do governo federal de tomar a educação como área prioritária para a política nacional e teve impacto sobre todas as áreas da educação.

Na educação tecnológica, em 2003 eram 141 escolas técnicas federais em funcionamento. No final de 2009, 254, com 244 mil matrículas em todo o país. Na rede pública federal deeducação superior, na modalidade presencial, em 2003 eram 106,8 mil vagas. No final de 2009, 186,9 mil vagas. No ProUni, foram concedidas 596 mil bolsas até o final de 2009 e 351 mil contratos de financiamento firmados com o Fies ${ }^{29}$.

Em relação à educação básica, apresentamos a seguir os dados.

\section{TABELA 130}

Taxa de escolarização líquida nas faixas etárias de 7 a 14 e de 15 a 17 anos, segundo sexo, cor/raça e localização (Brasil e regiões, 1992*, 2005 e 2008)

\begin{tabular}{|c|c|c|c|c|c|c|}
\hline \multirow{2}{*}{$\begin{array}{l}\text { Características } \\
\text { Selecionadas }\end{array}$} & \multicolumn{3}{|c|}{ Fundamental: 7 a 14 anos } & \multicolumn{3}{|c|}{ Médio: 15 a 17 anos } \\
\hline & 1992 & 2005 & 2008 & 1992 & 2005 & 2008 \\
\hline Total & 81,4 & 94,4 & 94,9 & 18,2 & 45,3 & 50,4 \\
\hline Norte & 82,5 & 93,1 & 93,6 & 11,7 & 30,7 & 39,7 \\
\hline Nordeste & 69,7 & 92,4 & 94,3 & 9,5 & 30,1 & 36,4 \\
\hline Sudeste & 88,0 & 95,8 & 95,7 & 24,3 & 57,4 & 61,9 \\
\hline Sul & 86,9 & 95,9 & 95,2 & 23,1 & 53,6 & 56,4 \\
\hline Centro-Oeste & 85,9 & 94,7 & 94,5 & 17,5 & 45,9 & 51,8 \\
\hline
\end{tabular}

Sexo

\begin{tabular}{|c|c|c|c|c|c|c|}
\hline Masculino & 79,9 & 94,1 & 94,9 & 15,1 & 40,6 & 44,4 \\
\hline Feminino & 82,7 & 94,7 & 94,9 & 21,3 & 50,1 & 56,8 \\
\hline
\end{tabular}

Cor/raça

\begin{tabular}{l|c|c|c|c|c|c}
\hline Branca & 87,5 & 95,4 & 95,4 & 27,1 & 56,6 & 61,0 \\
\hline Preta e Parda & 75,3 & 93,6 & 94,7 & 9,2 & 35,6 & 42,2 \\
\hline
\end{tabular}

Localização

\begin{tabular}{|c|c|c|c|c|c|c|}
\hline Rural & 66,5 & 92,3 & 94,3 & 5,3 & 24,7 & 33,3 \\
\hline Urbana & 86,2 & 95,0 & 95,1 & 22,3 & 50,4 & 54,3 \\
\hline
\end{tabular}

* Excluindo a população rural dos estados RO, AC, AM, RR, PA e AP.

Fonte: IBGE, “Pesquisa Nacional por Amostra de Domicílios, PNAD”, elaborada por Inep/DTDIE.
[28] Fonte: Leis Orçamentárias Anuais, disponíveis no site do Ministério do Planejamento <http://www. planejamento.gov.br».

[29] “Caderno Destaques”. Brasília: Presidência da República, mar. 2010, em http://www. planalto.gov.br.

[30] As Tabelas 1 e 2 foram reproduzidas do relatório "Objetivos de desenvolvimento do milênio: relatório nacional de acompanhamento". Brasília: Presidência da República, 2010. 
TABELA 2

Taxa de alfabetização das pessoas de 15 a 24 anos de idade, segundo sexo, cor/raça e localização (Brasil e regiões, 1992*, 2005 e 2008)

\begin{tabular}{|c|c|c|c|}
\hline \multirow{2}{*}{$\begin{array}{l}\text { Características } \\
\text { Selecionadas }\end{array}$} & \multicolumn{3}{|c|}{ Taxa de alfabetização } \\
\hline & 1992 & 2005 & 2008 \\
\hline Total & 91,3 & 97,2 & 97,8 \\
\hline Norte & 94,0 & 96,8 & 97,5 \\
\hline Nordeste & 80,0 & 93,7 & 95,7 \\
\hline Sudeste & 96,5 & 98,9 & 99,0 \\
\hline Sul & 96,8 & 98,8 & 99,0 \\
\hline Centro-Oeste & 95,4 & 98,7 & 98,8 \\
\hline \multicolumn{4}{|l|}{ Sexo } \\
\hline Masculino & 89,2 & 96,2 & 97,2 \\
\hline Feminino & 93,5 & 98,1 & 98,5 \\
\hline \multicolumn{4}{|l|}{ Cor/raça } \\
\hline Branca & 95,6 & 98,4 & 98,7 \\
\hline Preta e Parda & 86,8 & 96,0 & 97,3 \\
\hline \multicolumn{4}{|l|}{ Localização } \\
\hline Rural & 94,8 & 92,6 & 94,6 \\
\hline Urbana & 78,8 & 98,1 & 98,5 \\
\hline
\end{tabular}

* Exclusive Excluindo a população rural dos estados RO, AC,AM, RR, PAeAP.

Fonte: IBGE, “Pesquisa Nacional por Amostra de Domicílios, PNAD”, elaborada por Inep/DTDIE.

Esses dados, produzidos para o Relatório Nacional de Acompanhamento dos Objetivos de Desenvolvimento do Milênio, indicam que, embora os índices de alfabetização tenham crescido, o ensino médio continua sendo o ponto de parada da trajetória escolar dos estudantes brasileiros e onde as desigualdades entre as regiões do país, entre brancos e negros e entre as áreas urbana e rural emergem. Várias ações foram realizadas pelo Ministério da Educação e pelo governo como um todo, com a Secretaria de Políticas de Promoção da Igualdade Racial (Seppir), mas ainda foram insuficientes para reverter o quadro de desigualdades existentes no país em relação à educação.

As políticas de educação são eminentemente de longo prazo e as mudanças operadas principalmente nos últimos quatro anos ainda não produziram resultados. No entanto, com a ampliação dos recursos para a educação básica e a expansão da educação tecnológica, que engloba inclusive o ensino médio, podemos dizer que há um quadro institucional favorável para que o ensino médio possa se expandir e qualificar na próxima década. Além disso, a capilarização das instituições criadas com a expansão da rede de educação tecnológica e da 
rede pública de educação superior operada pelo Reuni, bem como a responsabilização da Capes pela formação dos professores podem ensejar um quadro de diminuição das desigualdades territoriais, outro ponto crítico que sobressai dos dados apresentados. Acima de tudo, a mudança contida na Emenda Constitucional no 59 , que deu nova redação ao artigo 208 da Constituição da República, tornou obrigatória a educação dos 4 aos 17 anos de idade.

\section{PERSPECTIVAS PARA O FUTURO}

O contexto atual da educação brasileira está muito longe de ser tranqüilizador. $O$ ensino fundamental foi expandido, mas não é de boa qualidade, como indicam os dados utilizados pelo próprio MEC para estabelecer as metas do Ideb ${ }^{31}$. O ensino médio ainda apresenta taxas de matrícula bastante inferiores às desejáveis. Contudo, as perspectivas podem despertar, sim, algum otimismo. Entrará em discussão no Congresso Nacional nos próximos meses o novo Plano Nacional de Educação, que deverá valer para os próximos dez anos. Pode-se constatar, a partir do Documento de Referência da Conferência Nacional de Educação, que serão reconhecidos os esforços realizados nos últimos anos e os próximos passos serão conseqüência do que já foi feito. O caminho é de aperfeiçoamento, o que certamente representa uma situação mais confortável do que a de trilhar caminhos absolutamente novos ou do que recuar em trajetórias equivocadas. Além disso, a aprovação da Emenda Constitucional n ${ }^{\circ} 59$ acena para o reconhecimento de que, para o futuro, é necessário que a educação seja realmente uma prioridade nacional e uma política federal, envolvendo todos os entes federativos, e que isso seja traduzido no aumento de recursos a ela destinados, inclusive vinculados ao PIB, e não somente à receita de impostos.

O caminho da nacionalização da educação, assumido na última gestão do governo Lula com o PDE, parece ser irrevogável. Se os resultados estimados para 2022 serão alcançados é algo que não pode ser assegurado de forma absoluta. Mas a meta foi colocada, e objetivos intermediários e instrumentais para o seu alcance foram estabelecidos. Algo foi conquistado. E isso sem dúvida deve ser comemorado.

\section{CONSIDERAÇõES FINAIS}

A qualidade e a extensão da educação no Brasil estão longe de serem consideradas satisfatórias. No entanto, o que se pode perceber na política dos últimos anos é que importantes passos foram dados no diagnóstico dos problemas, na forma com que foram apontados no 
Recebido para publicação em 15 de maio de 2010 .

\section{NOVOS ESTUDOS}

CEBRAP

87 , julho 2010

pp. 131-143
Plano Nacional de Educação e na organização institucional para o encaminhamento de soluções para os mesmos.

A gestão do Ministério da Educação dos últimos anos, em sua ousada iniciativa institucional, estabeleceu bases para uma nova relação entre os setores público e privado, como se pode perceber no novo sistema regulatório da educação superior, no ProUni e na reforma do Sistema S.A União avocou o seu papel de agente regulador e organizador da educação nacional e estabeleceu obrigações e compromissos para o setor privado que antes não estavam presentes.

O equacionamento da solução dos problemas realizado pelo PDE e pela série de medidas que o constituíram foi uma contribuição do governo Lula, cujos resultados ainda não podem ser medidos em razão de a política educacional ser essencialmente de longo prazo. Masé inegável que as mudanças estabelecidas, dado o contexto nacional, foram tomadas na direção correta. Isto é o que indica o documento de referência da Conferência Nacional de Educação, realizada em 2010 , que está subsidiando a elaboração do novo Plano Nacional de Educação. O documento incorpora soluções institucionais e, inclusive, expressões, como "visão sistêmica da educação", que foram cunhadas no âmbito do PDE. Sem dúvida hoje a educação tornou-se uma questão nacional não só no discurso de governos dos diversos entes federativos, mas em suas instituições. Isto é o que se depreende das inovações legislativas de iniciativa do Executivo nos últimos anos.

Tudo isto certamente contribui para transformar a educação em uma questão e uma prioridade nacionais, processo que foi coroado com a Emenda Constitucional $n^{\circ} 59$, que estabeleceu um novo tratamento constitucional à educação, ampliando a responsabilidade de todos os atores envolvidos com a área. Saibamos, então, aproveitar esse cenário favorável.

MARIA APARECIDA AZEVEDo AbReU é doutora em Ciência Política pela USP e pesquisadora do Instituto de Pesquisa Econômica Aplicada (Ipea). 